\title{
The learning curve of video-assisted thoracoscopic sleeve lobectomy in a high-volume pulmonary center
}

Jiajun Deng, MD, Lei Jiang, MD, Shenghui Li, MD, Lei Zhang, MD, Yifan Zhong, MD, Dong Xie, MD, PhD, and Chang Chen, MD, PhD

\section{ABSTRACT}

Objectives: To evaluate the time course and caseload required to achieve proficiency by plotting the learning curve of video-assisted thoracoscopic sleeve lobectomy.

Methods: We reviewed 127 cases of video-assisted thoracoscopic sleeve lobectomy by a single surgeon at Shanghai Pulmonary Hospital to evaluate its learning curve using the cumulative sum (CUSUM) analysis. The changes of perioperative outcomes were assessed.

Results: The inflection points of the CUSUM curve were around case 30 and 90 , according to which 3 phases were identified: Phase I, Phase II, and Phase III. Significant downtrends were observed regarding operative time (Phase I, 194 [173-233 minutes] vs Phase II, 172 [142-215 minutes] vs Phase III, 138 [117-164 minutes], $P<.05$, all), blood loss (Phase I, 200 [100-238 mL] vs Phase II, $100[50-200 \mathrm{~mL}]$ vs Phase III, 50 [50-100 mL]; $P<.05$, all), drainage duration (Phase I $[5.53 \pm 1.11$ days $]$ vs Phase II $[4.52 \pm 1.38$ days]; $P<.05)$, and length of postoperative stays (Phase I $[6.60 \pm 1.13$ days $]$ vs Phase II $[5.68 \pm 1.47$ days $], P<.05)$. The rate of severe complications significantly decreased from Phase I to Phase II $(P=.03)$.

Conclusions: Thirty cases should be accumulated to lay the technical foundation, and 90 cases were required to achieve proficiency. The focus should now shift to providing sufficient training opportunities for centers wanting to implement this technique. (JTCVS Techniques 2021;9:143-52)

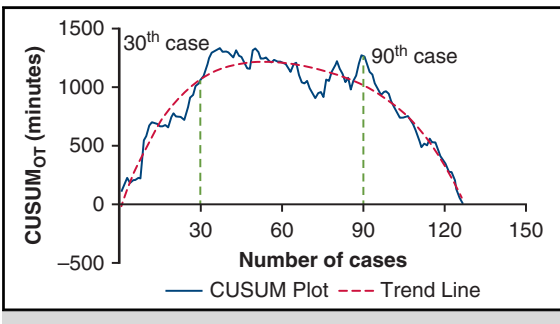

30 cases and 90 cases are needed to lay the technical foundation and achieve proficiency.

\section{CENTRAL MESSAGE}

Thirty cases are needed to lay the technical foundation and 90 cases are required to achieve proficiency.

\section{PERSPECTIVE}

The wide application of VATS sleeve lobectomy is currently restricted due to its technical difficulties. The learning curve of the procedure has significant implications for technical population, education, and patients' safety. A clear understanding of the learning curve should be profitable for surgeons aiming to master the surgical approach and institutions wanting to adopt this new technique.

See Commentaries on pages 153 and 155 .
Video clip is available online.

In the past few decades, sleeve lobectomy has been reported to yield a lower rate of operative mortality, fewer complications, and noninferior oncologic outcomes compared with

\footnotetext{
From the Department of Thoracic Surgery, Shanghai Pulmonary Hospital, School of Medicine, Tongji University, Shanghai, China.

This study was supported by Shanghai Science and Technology Commission (20035800100), Shanghai Municipal Health Commission (2018ZHYL0102),

Fundamental Research Funds for the Central Universities (22120190216).

Drs Deng and Jiang contributed equally to this work.

Drs Xie and Chen are co-senior authors.

Received for publication Jan 12, 2021; accepted for publication July 9, 2021; available ahead of print July 20, 2021.
}

pneumonectomy. ${ }^{1-5}$ Recently, with the development of video-assisted thoracic surgery (VATS), which was demonstrated to have appreciably lower risks of morbidity and mortality than conventional thoracotomy, VATS sleeve lobectomy has become an alternative approach for centrally located lesions. ${ }^{6-10}$

VATS sleeve lobectomy has become a preferred surgical approach in high-volume centers. However, in primary hospitals, its routine application is still limited. The

\footnotetext{
Address for reprints: Chang Chen, MD, $\mathrm{PhD}$, and Dong Xie, MD, PhD, Department of Thoracic Surgery, Shanghai Pulmonary Hospital, Tongji University School of Medicine, Shanghai, 200443, China (E-mail: chenthoracic@163.com or kongduxd@163.com). 2666-2507

Copyright (C) 2021 The Author(s). Published by Elsevier Inc. on behalf of The American Association for Thoracic Surgery. This is an open access article under the CC BY-NC-ND license (http://creativecommons.org/licenses/by-nc-nd/4.0/). https://doi.org/10.1016/j.xjtc.2021.07.006
} 


\section{Abbreviations and Acronyms \\ $\mathrm{CT}=$ computed tomography \\ CUSUM $=$ cumulative sum \\ VATS $=$ video-assisted thoracic surgery}

potential reason might be the technical difficulties of this complex procedure. ${ }^{11}$ In addition, insufficient surgical expertise may obscure the inherent benefits of the thoracoscopic approach. ${ }^{12-14}$ To achieve proficiency, where robust oncologic tenets and the greatest safety parameters are guaranteed, it is necessary to complete an apprenticeship period. However, it's still unknown how many cases are required in the learning process, an understanding of which is conducive to appropriately allocate the time and human resources need for the learning period. In such instances, it is necessary to develop a learning curve. Therefore, the purpose of this research is to evaluate the feasibility and learning curve of this technique by analyzing the changes of perioperative results during the learning phase of VATS sleeve lobectomy.

\section{METHODS \\ Patients}

In this study, we reviewed 127 patients undergoing VATS sleeve lobectomy by a senior surgeon at Shanghai Pulmonary Hospital between January 2014 and June 2020. The surgeon in our study performed more than 50 cases of open sleeve lobectomy before 2014 , and he annually conducted 800 thoracoscopic surgery and 30 VATS sleeve lobectomy during the learning phase (Figure E1). Admitted were all patients $(\mathrm{n}=208)$ in whom a thoracoscopic sleeve lobectomy was conducted. Patients $(n=81)$ who were diagnosed as having benign disease and underwent carinal reconstruction, pulmonary arterioplasty, extended sleeve lobectomy, or a combination of other pulmonary resections were excluded (Figure E2). Finally, 127 patients were included in our study. Official approval was given by the institutional review board (L20-334Y, 2020-08-25) and the requirement for consent was waived.

\section{Preoperative Evaluation and Follow-up Protocol}

Preoperative assessments included complete blood tests serum biochemistry tests, electrocardiogram, pulmonary function test, chest radiograph, computed tomography (CT) scan/contrast-enhanced CT, bone scan, and cerebral magnetic resonance imaging. Endobronchial ultrasound-guided transbronchial needle aspiration or positron emission tomography were performed if necessary. The final decision regarding the surgical approach was based on patients' performance status and resectability of the lesion. Every patient had standardized postoperative care regardless of the surgical approach. Follow-up information was obtained through telephone calls or outpatient examinations. Chest and abdominal CT scans were performed at 3, 6, and 12 months after surgery and annually for 5 years thereafter. Cerebral magnetic resonance imaging and bone scan were annually performed for 5 years or if there were any signs of recurrence. It was recommended to perform positron emission tomography/CT scan or biopsy to confirm recurrence. All patients finished follow-up for the present study up to September 30, 2020.

\section{Surgical Technique}

Sleeve lobectomy can be performed when the tumor is at the entrance of a lobar bronchus, or when there are exophytic tumors in a main-stem

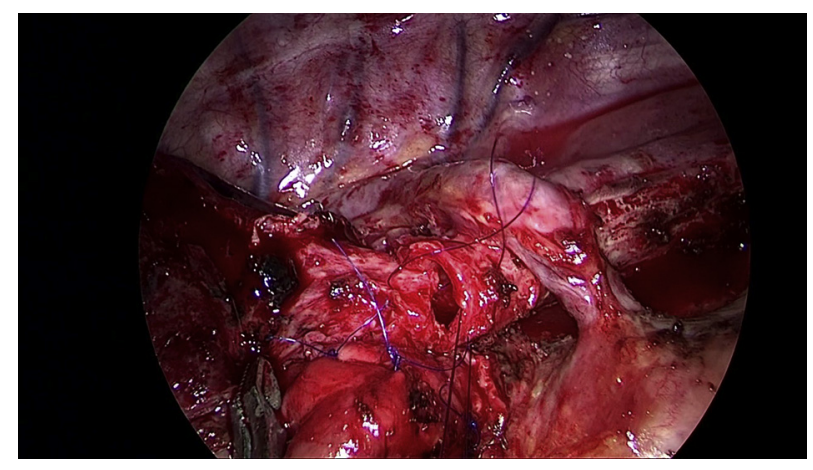

VIDEO 1. Bronchial anastomosis in video-assisted thoracoscopic right upper sleeve lobectomy. Video available at: https://www.jtcvs.org/article/ S2666-2507(21)00476-4/fulltext.

bronchus or when submucosal signs indicate cancer extension. In our experience, surgeons who performed more than 200 cases of VATS lobectomy could be recommended to conduct VATS sleeve lobectomy.

The patients were positioned in a lateral decubitus position. For uniportal VATS, the incision was performed at the fourth or fifth intercostal space. For triportal VATS, incisions were adopted similar to standard VATS lobectomy. After the pulmonary vessels and fissures were handled, the bronchus was resected with at least $0.5-\mathrm{cm}$ margins, followed by frozen-section analysis. We preferred to using a continuous absorbable suture (polydioxanone 3/0) to complete the end-to-end bronchial anastomoses (Video 1). A systematic lymph node dissection was routinely performed in our study. Bronchoscopy was performed to check the integrity of the anastomosis and clear secretions. Detailed descriptions of the surgical technique have been published in our previous study for both uniportal or triportal thoracoscopic sleeve lobectomy. ${ }^{7}$

\section{Data Collection}

Baseline characteristics and perioperative outcomes were collected. All tumors were staged according to the eighth edition of the TNM (tumor, node, metastases) staging for lung cancer. ${ }^{15}$ Comorbidity was described according to the Charlson Comorbidity Index. ${ }^{16}$ Postoperative complications were described according to the Clavien-Dindo Classifications. ${ }^{17}$ Prolonged air leakage was defined as lasting for more than 5 days after the operation. Perioperative mortality was defined as death within 30 days of the surgery.

\section{Cumulative Sum (CUSUM) Analysis}

CUSUM reflected the running total of the differences between the individual data points and the mean value of all data points. In the present study, the cases were chronologically ranked from the first to the latest date of VATS sleeve lobectomy. The CUSUM was used to analyze operation time. The consecutive procedure outcomes were presented in the CUSUM chart. CUSUM $\mathrm{OT}_{\mathrm{OT}}$ was calculated as follows: CUSUM $_{\mathrm{OT}}=\sum_{i=0}^{n}\left(x_{i}-u\right)$ where $x_{\mathrm{i}}$ and $u$ represent an individual and the mean overall operative time, respectively, and OT represents operativetime. ${ }^{18,19}$ Furthermore, we established a trend line to show the change in the slope of the learning curve, based on which the inflection points were identified.

\section{Statistical Analysis}

Based on the inflection points, we separated the curve into 3 distinct phases: Phase I, Phase II, and Phase III. A subgroup analysis was conducted by comparing the perioperative outcomes of 3 periods to assess a potential learning curve effect. All statistical analyses were carried out with SPSS, version 22 (IMB Corp, Inc, Armonk, NY). Normally distributed continuous 
TABLE 1. Demographic and clinical characteristics of the patients

\begin{tabular}{|c|c|c|c|c|c|c|}
\hline Parameters & $\begin{array}{c}\text { Total } \\
(\mathrm{n}=127)\end{array}$ & $\begin{array}{l}\text { Phase I } \\
(\mathbf{n}=\mathbf{3 1})\end{array}$ & $\begin{array}{l}\text { Phase II } \\
(n=60)\end{array}$ & $\begin{array}{l}\text { Phase III } \\
(n=36)\end{array}$ & $\begin{array}{c}P \text { value } \\
\text { (Phase I vs II) }\end{array}$ & $\begin{array}{c}P \text { value } \\
\text { (Phase II vs III) } \\
\end{array}$ \\
\hline Age, y & $63.44 \pm 8.45$ & $61.30 \pm 8.46$ & $63.90 \pm 8.07$ & $64.44 \pm 8.98$ & .160 & .760 \\
\hline $\begin{array}{l}\text { Sex, n }(\%) \\
\quad \text { Male } \\
\text { Female }\end{array}$ & $\begin{array}{r}104(81.9 \%) \\
23(18.1 \%)\end{array}$ & $\begin{array}{r}25(80.6 \%) \\
6(19.4 \%)\end{array}$ & $\begin{array}{l}49(81.7 \%) \\
11(18.3 \%)\end{array}$ & $\begin{array}{r}30(83.3 \%) \\
6(16.7 \%)\end{array}$ & .852 & .845 \\
\hline BMI & $23.61 \pm 2.57$ & $23.46 \pm 2.64$ & $23.74 \pm 2.69$ & $23.51 \pm 2.37$ & .642 & .673 \\
\hline $\begin{array}{l}\text { Smoking history, n (\%) } \\
\text { Yes } \\
\text { No }\end{array}$ & $\begin{array}{l}57(44.9 \%) \\
70(55.1 \%)\end{array}$ & $\begin{array}{l}14(45.2 \%) \\
17(54.8 \%)\end{array}$ & $\begin{array}{l}26(43.3 \%) \\
34(56.7 \%)\end{array}$ & $\begin{array}{l}17(47.2 \%) \\
19(52.8 \%)\end{array}$ & .654 & .711 \\
\hline $\begin{array}{r}\mathrm{CCI} \\
0 \\
1 \\
2 \\
3\end{array}$ & $\begin{array}{c}67(52.7 \%) \\
42(33.1 \%) \\
10(7.9 \%) \\
8(6.3 \%)\end{array}$ & $\begin{array}{c}16(51.6 \%) \\
10(32.2 \%) \\
3(9.7 \%) \\
2(6.5 \%)\end{array}$ & $\begin{array}{c}27(45.0 \%) \\
24(40.0 \%) \\
5(8.3 \%) \\
4(6.7 \%)\end{array}$ & $\begin{array}{l}24(66.7 \%) \\
8(22.2 \%) \\
2(5.6 \%) \\
2(5.6 \%)\end{array}$ & .804 & .252 \\
\hline FEV1 \% & $77.52 \pm 8.49$ & $78.63 \pm 7.73$ & $77.95 \pm 8.65$ & $75.87 \pm 8.82$ & .716 & .260 \\
\hline $\begin{array}{l}\text { Pathologic stage, n (\%) } \\
\text { IA } \\
\text { IB } \\
\text { IIA } \\
\text { IIB } \\
\text { IIIA } \\
\text { IIIB }\end{array}$ & $\begin{array}{l}36(28.3 \%) \\
18(14.2 \%) \\
10(7.9 \%) \\
24(18.9 \%) \\
35(27.6 \%) \\
4(3.1 \%)\end{array}$ & $\begin{array}{l}7(22.6 \%) \\
4(12.9 \%) \\
2(6.5 \%) \\
8(25.8 \%) \\
9(29.0 \%) \\
1(3.2 \%)\end{array}$ & $\begin{aligned} & 21(35.0 \%) \\
& 11(18.3 \%) \\
& 7(11.7 \%) \\
& 8(13.3 \%) \\
& 11(18.3 \%) \\
& 2(3.3 \%)\end{aligned}$ & $\begin{aligned} 8 & (22.2 \%) \\
3 & (8.3 \%) \\
1 & (2.8 \%) \\
8 & (22.2 \%) \\
15 & (41.7 \%) \\
1 & (2.8 \%)\end{aligned}$ & .316 & .062 \\
\hline Neoadjuvant chemotherapy, n (\%) & $14(11.0 \%)$ & $4(12.9 \%)$ & $6(10.0 \%)$ & $4(11.1 \%)$ & .635 & .863 \\
\hline Adjuvant chemotherapy, n (\%) & $84(66.1 \%)$ & $20(64.5 \%)$ & $39(65.0 \%)$ & $25(69.4 \%)$ & .875 & .655 \\
\hline Adjuvant radiotherapy & $6(3.9 \%)$ & $1(3.2 \%)$ & $3(5.0 \%)$ & $2(5.6 \%)$ & .718 & .906 \\
\hline Lesion size, $\mathrm{cm}$ & $3.41 \pm 1.94$ & $3.32 \pm 1.50$ & $3.46 \pm 2.37$ & $3.39 \pm 1.46$ & .769 & .876 \\
\hline $\begin{array}{l}\text { Resection site } \\
\text { LUL } \\
\text { LLL } \\
\text { RUL } \\
\text { RML } \\
\text { RLL }\end{array}$ & $\begin{array}{c}14(11.1 \%) \\
31(24.6 \%) \\
42(33.3 \%) \\
4(3.2 \%) \\
35(27.8 \%)\end{array}$ & $\begin{array}{c}3(10.0 \%) \\
7(23.3 \%) \\
10(33.3 \%) \\
1(3.3 \%) \\
9(30.0 \%)\end{array}$ & $\begin{array}{c}6(10.0 \%) \\
15(25.0 \%) \\
18(28.3 \%) \\
2(3.3 \%) \\
19(33.3 \%)\end{array}$ & $\begin{array}{c}5(13.9 \%) \\
9(25.0 \%) \\
14(38.9 \%) \\
1(2.8 \%) \\
7(19.4 \%)\end{array}$ & .992 & .620 \\
\hline
\end{tabular}

Data are presented as median (interquartile range), mean $\pm \mathrm{SD}$, or number (percentage). $B M I$, Body mass index; $C C I$, Charlson comorbidity index; $F E V I \%$, forced expiratory volume in 1 second to forced vital capacity ratio; $L U L$, left upper lobe; $L L L$, left lower lobe; $R U L$, right upper lobe; $R M L$, right middle lobe; $R L L$, right lower lobe.

variables were presented as mean \pm standard deviation and compared by independent-samples $t$ test. Skewed data were exhibited as median with interquartile range and analyzed by Mann-Whitney $U$ test. Categoric variables were exhibited as frequency and proportions and compared between 2 groups using the $\chi^{2}$ test. The overall survival and recurrence-free survival were evaluated by the Kaplan-Meier method.

\section{RESULTS}

\section{Patient Characteristics}

Of 127 consecutive VATS sleeve lobectomy performed between January 2014 and June 2020, 45 (35.4\%) were left sleeve lobectomy, and $81(63.7 \%)$ were right. These patients consisted of $104(81.9 \%)$ male patients and 23 $(19.4 \%)$ female patients with a mean age of $63.44 \pm 8.45$ years old. In total, $85.8 \%$ of patients ( $\mathrm{n}=109$ ) had mild or no comorbidities (Charlson comorbidity index $\leq 1$ ) before the operation. More detailed patient characteristics are presented in Table 1.

\section{Perioperative Outcomes}

The perioperative outcomes of the patients were presented in Table 2. In the entire series, the median operative time and blood loss were 170 (140-202) minutes and 100 (50-200) minutes, respectively. Patients stayed a mean of $5.82 \pm 1.48$ days in the hospital after surgery, and their mean duration of postoperative chest drainage was $4.63 \pm 1.38$ days. Sixteen patients (12.5\%) developed postoperative complications, which were severe $(\geq$ III according to the Clavien-Dindo classification) in 10 patients $(7.9 \%)$. Complications included pneumonia ( $\mathrm{n}=16)$, hemothorax $(\mathrm{n}=4)$, perioperative blood 
TABLE 2. Interphase comparisons of perioperative parameters

\begin{tabular}{|c|c|c|c|c|c|c|}
\hline Parameters & $\begin{array}{c}\text { Total } \\
(\mathbf{n}=\mathbf{1 2 7})\end{array}$ & $\begin{array}{l}\text { Phase I } \\
(\mathbf{n}=31)\end{array}$ & $\begin{array}{l}\text { Phase II } \\
(\mathbf{n}=60)\end{array}$ & $\begin{array}{c}\text { Phase III } \\
(\mathbf{n}=\mathbf{3 6})\end{array}$ & $\begin{array}{c}P \text { value } \\
\text { (phase I vs II) }\end{array}$ & $\begin{array}{c}P \text { value } \\
\text { (Phase II vs III) }\end{array}$ \\
\hline $\begin{array}{l}\text { Operative time, } \min \\
\text { Median (IQR) }\end{array}$ & $170(140-202)$ & $194(173-233)$ & $172(142-215)$ & $138(117-164)$ & .019 & $<.001$ \\
\hline $\begin{array}{l}\text { Blood loss, ml } \\
\text { Median (IQR) }\end{array}$ & $100(50-200)$ & $200(100-238)$ & $100(50-200)$ & $50(50-100)$ & .004 & .001 \\
\hline LN stations & $5.60 \pm 1.13$ & $5.33 \pm 1.32$ & $5.47 \pm 1.10$ & $6.03 \pm 0.93$ & .590 & .060 \\
\hline LN numbers & $13.98 \pm 5.21$ & $12.97 \pm 3.49$ & $13.48 \pm 4.76$ & $14.61 \pm 5.21$ & .600 & .281 \\
\hline Conversion to open thoracotomy & $1(0.7 \%)$ & $1(3.1 \%)$ & 0 & 0 & .160 & 1.000 \\
\hline Length of stay, $d$, mean \pm SD & $5.82 \pm 1.48$ & $6.60 \pm 1.13$ & $5.68 \pm 1.47$ & $5.39 \pm 1.55$ & .003 & .354 \\
\hline Drainage duration, $\mathrm{d}$, mean $\pm \mathrm{SD}$ & $4.63 \pm 1.38$ & $5.53 \pm 1.11$ & $4.52 \pm 1.38$ & $4.08 \pm 1.25$ & .001 & .127 \\
\hline $\begin{array}{l}\text { Clavien-Dindo } \\
\geq \text { III, n }(\%)\end{array}$ & $10(7.9 \%)$ & $6(19.4 \%)$ & $3(5.0 \%)$ & $1(2.7 \%)$ & .025 & .598 \\
\hline \multicolumn{7}{|l|}{ Complications, $\mathrm{n}(\%)$} \\
\hline Pneumonia & $16(12.6 \%)$ & $7(23.3 \%)$ & $6(10.0 \%)$ & $3(8.3 \%)$ & .090 & .786 \\
\hline Hemothorax & $4(3.1 \%)$ & $1(3.3 \%)$ & $2(3.3 \%)$ & $1(2.8 \%)$ & 1.000 & .880 \\
\hline Perioperative blood transfusion & $8(6.3 \%)$ & $4(13.3 \%)$ & $3(5.0 \%)$ & $1(2.8 \%)$ & .164 & .406 \\
\hline Chylothorax & $3(2.4 \%)$ & $2(6.7 \%)$ & $1(1.7 \%)$ & 0 & .213 & .436 \\
\hline Bronchopleural fistula & $4(3.1 \%)$ & $3(10.0 \%)$ & $1(1.7 \%)$ & 0 & .071 & .436 \\
\hline Prolonged air leak & $9(7.1 \%)$ & $4(13.3 \%)$ & $3(5.0 \%)$ & $2(5.6 \%)$ & .164 & .906 \\
\hline Empyema & $4(3.1 \%)$ & $3(10.0 \%)$ & $1(1.7 \%)$ & 0 & .071 & .436 \\
\hline Pulmonary embolism & $1(1.7 \%)$ & 0 & $1(1.7 \%)$ & 0 & .477 & .436 \\
\hline Recurrence, n (\%) & $36(28.3 \%)$ & $11(36.7 \%)$ & $19(31.7 \%)$ & $6(16.7 \%)$ & .635 & .105 \\
\hline Local-regional & $19(15.0 \%)$ & $6(20.0 \%)$ & $11(13.3 \%)$ & $2(5.6 \%)$ & .849 & .077 \\
\hline Distal & $17(13.4 \%)$ & $5(16.7 \%)$ & $8(13.1 \%)$ & $4(11.1 \%)$ & .672 & .750 \\
\hline
\end{tabular}

Data are presented as median (interquartile range), mean (median, interquartile range), or number (percentage). IQR, Interquartile range; $L N$, lymph node; $S D$, standard deviation.

transfusion ( $\mathrm{n}=8)$, chylothorax $(\mathrm{n}=3)$, bronchopleural fistula $(n=4)$, and prolonged air leak $(n=9)$. There was 1 patient $(0.8 \%)$ in Phase I who was converted to thoracotomy due to pulmonary artery hemorrhage. One patient $(0.8 \%)$ with a history of lower-extremity deep-vein embolism died of pulmonary embolism although perioperative anticoagulation management was taken. The overall median follow-up time of our cohort was 32.4 months. In total, 36 patients $(28.3 \%)$ experienced the recurrence of the disease, of whom 19 patients underwent local recurrence and $17 \mathrm{pa}-$ tients underwent distal recurrence. The overall and recurrence-free survival are presented in Figure E3.

\section{Cumulative Sum Analysis}

The learning curve for the operative time in VATS sleeve lobectomy is displayed in Figure 1. Based on the trend of the learning curve, 2 inflection points fell at the 30th case and the 90th case, respectively. Phase $\mathrm{I}(\mathrm{n}=30,1-30$ cases $)$ represented the initial experience with the technique. Phase II ( $\mathrm{n}=60,31-90$ cases) represented the further improvement of surgical skills. Phase III ( $\mathrm{n}=36,91-126$ cases) represented that technical proficiency was achieved. A visual inspection of the CUSUM plot showed that the cumulative operative time increased in Phase I, hit the plateau in Phase II, and decreased in Phase III (Figure 1).

\section{Subgroup Analysis}

Comparisons of perioperative parameters are presented in Table 2. The operative time improved from the median of 194 (173-233) minutes to 138 (117-164) minutes $(P<.05$, all, Figure $2, A)$. The estimated blood loss was observed to decrease from the median $200(100-238) \mathrm{mL}$ to $50(50-100) \mathrm{mL}(P<.05$, all, see Figure $2, B)$. The length of postoperative stays improved from the mean of $6.60 \pm 1.13$ days to $5.68 \pm 1.47$ days from Phase I to Phase

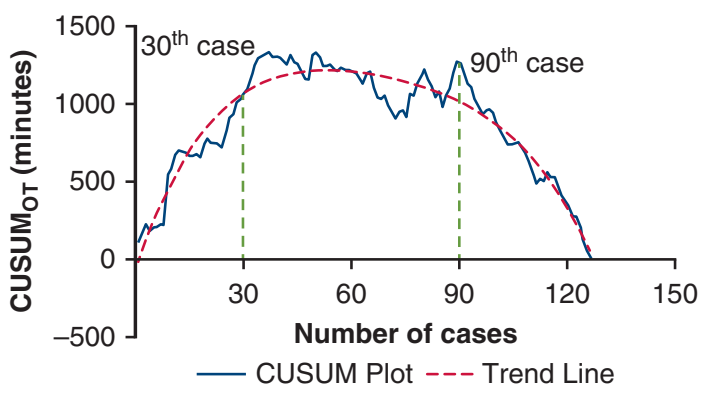

FIGURE 1. The CUSUM curve of operative time; 30 cases were needed to lay the technical foundation and 90 cases were necessary to achieve proficiency. Phase I: 1-30 cases, learning phase. Phase II: 31-90 cases, transition phase. Phase III: 91-126 cases, proficiency phase. CUSUM, Cumulative sum; $O T$, operative time. 


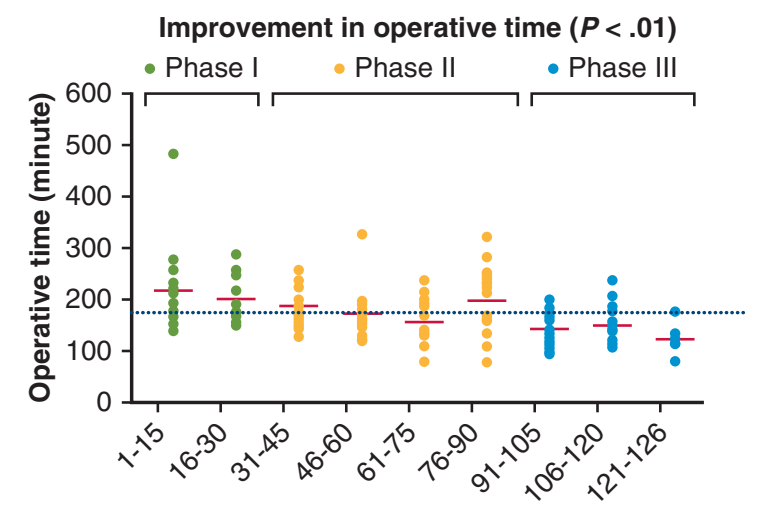

Number of cases

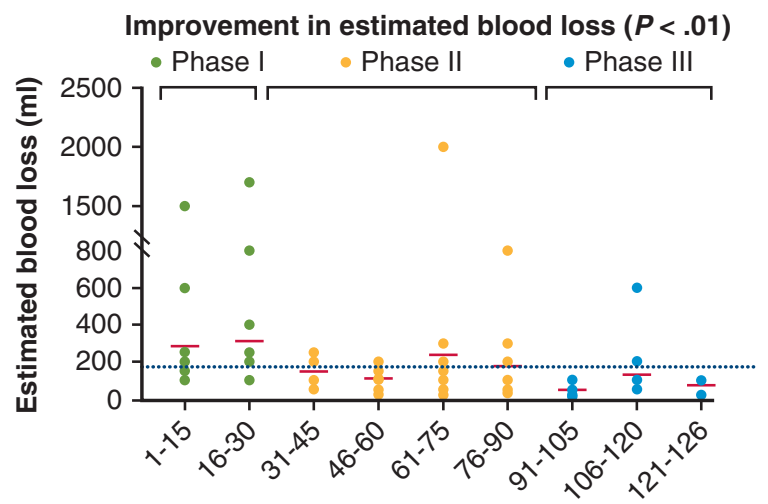

Number of cases

A ......... Overall Mean — Group Mean

B

FIGURE 2. Comparisons of intraoperative outcomes. A, Improvement of operative time. A significant decrease was observed both in Phase II and Phase III compared with Phase I. The circles represent the individual operative time in each patient. The blue dashed line reflects the mean operative time of all series. The red solid line reflects the mean operative time of each group. B, Improvement of estimated blood loss. A significant decrease was observed both in Phase II and Phase III compared with Phase I. The circles represent the individual blood loss in each patient. The blue dashed line reflects the mean estimated blood loss of all series. The red solid line reflects the mean estimated blood loss of each group.

II $(P<.05$; Figure 3, A), and the chest drainage duration reduced from the mean of $5.53 \pm 1.11$ days to $4.52 \pm 1.38$ days from Phase I to Phase II $(P<.05$; Figure 3, $B$ ).

The rate of severe complications was significantly reduced from $19.4 \%$ to $5.0 \%$ after 30 cases were conducted $(P=.025)$. The primary complication was pneumonia $(\mathrm{n}=16,12.6 \%)$. In Phase I, 4 patients $(13.3 \%)$ suffered prolonged air leaks, and 1 patient $(3.3 \%)$ who experienced hemothorax required reoperation. Two patients $(6.7 \%)$ represented chylothorax, one of whom was treated with thoracic duct ligation whereas the other recovered after conservative treatment. Three patients $(10.0 \%)$ experienced bronchopleural fistula, with one needing a surgical fistula repair. In Phase II, 3 patients $(5.0 \%)$ suffered prolonged air leaks, and 2 patients $(3.3 \%)$ experienced hemothorax with conservative treatment. One patient $(1.7 \%)$ represented with bronchopleural fistula and 1 patient $(1.7 \%)$ with represented chylothorax; they both recovered with conservative treatment. While in Phase III, only 1 patient

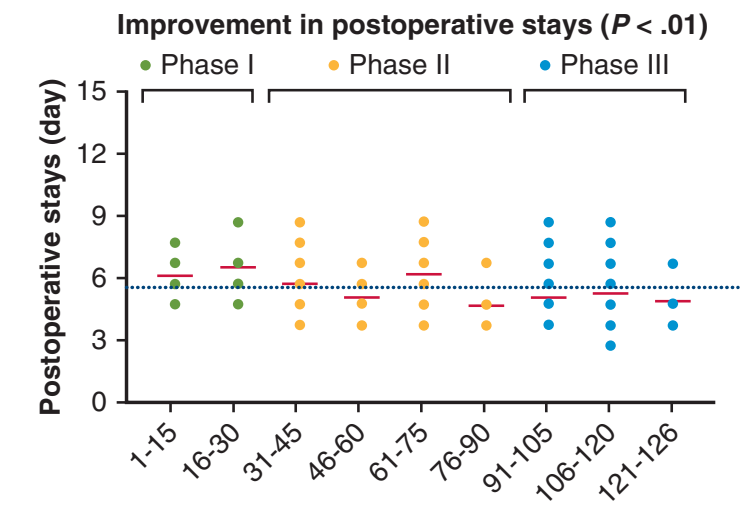

Number of cases

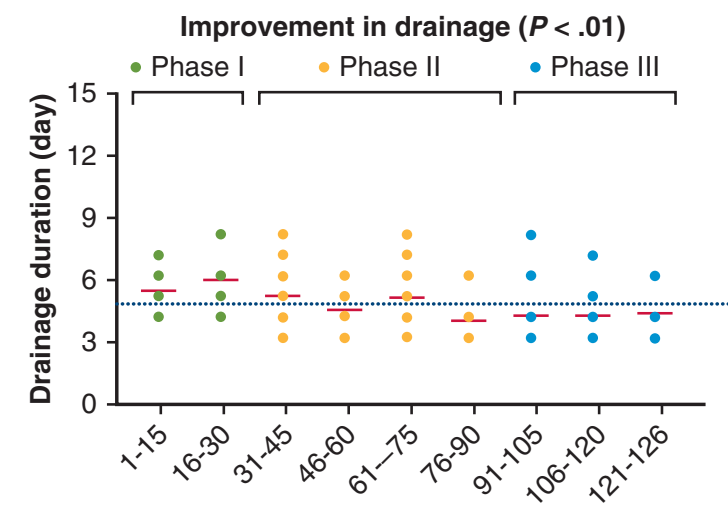

Number of cases

A ......... Overall Mean __ Group Mean

B

FIGURE 3. Comparisons of postoperative outcomes. A, Improvement of postoperative stay. A significant decrease was observed both in Phase II and Phase III compared with Phase I. The circles represent the individual postoperative stays in each patient. The blue dashed line reflects the mean postoperative stays of all sires. The red solid line reflects the mean postoperative stays of each group. B, Improvement of chest drainage. A significant decrease was observed both in Phase II and Phase III compared with Phase I. The circles represent the individual drainage duration in each patient. The blue dashed line reflects the mean drainage duration of all sires. The red solid line reflects the mean drainage duration of each group. 


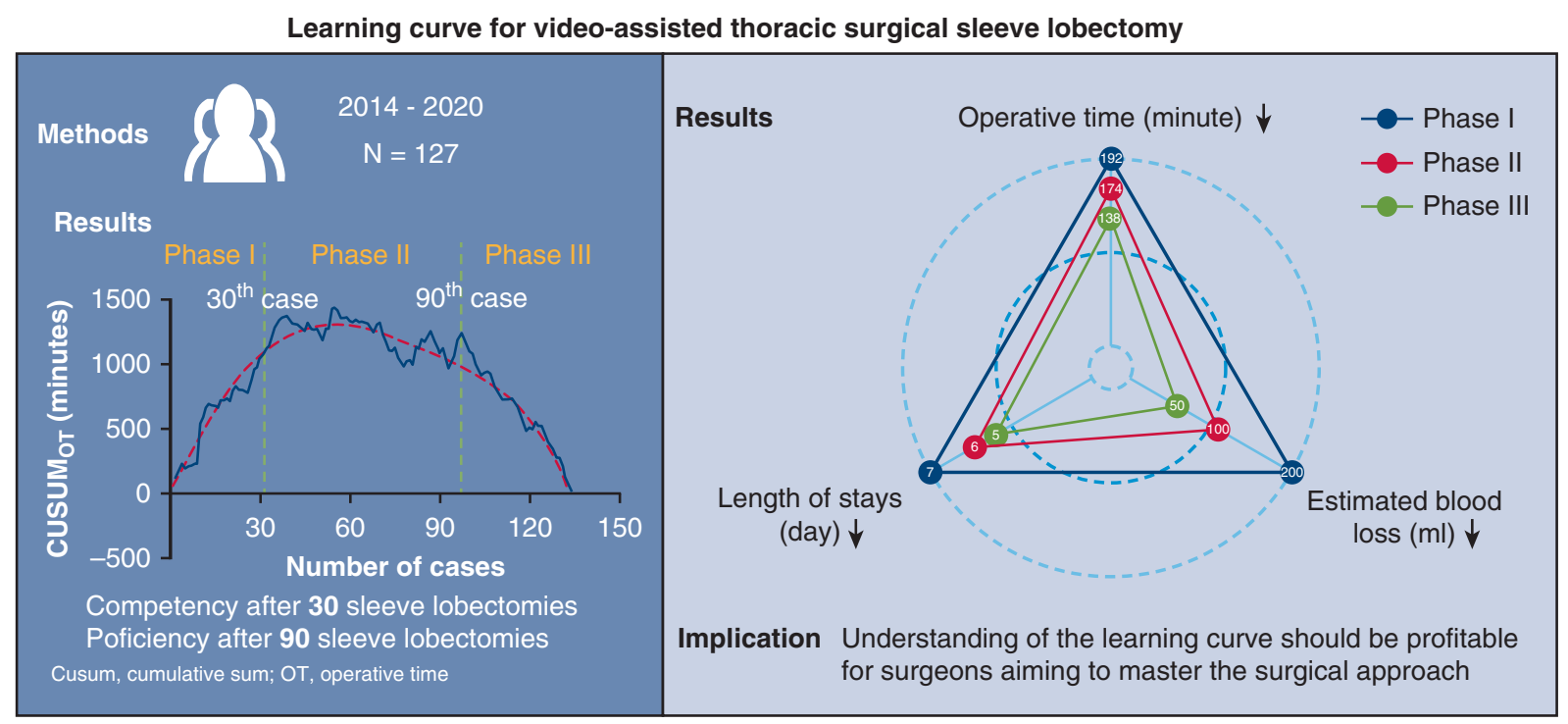

FIGURE 4. Thirty cases were needed to lay technical foundation and 90 cases were necessary to achieve proficiency. Perioperative outcomes including OT, estimated blood loss, and length of stays were improved as the learning curve developed. CUSUM, Cumulative sum; OT, operative time.

$(2.8 \%)$ suffered hemothorax and 2 patients $(5.6 \%)$ suffered prolonged air leaks. No patient presented chylothorax or bronchopleural fistula. Moreover, the rate of both local and distal recurrence was decreased, but the difference was not significant.

\section{DISCUSSION}

VATS sleeve lobectomy has been proved to be a safe and feasible surgical approach for centrally located diseases. ${ }^{7,20,21}$ Currently, it is only routinely performed in high-volume medical institutions owing to its technical difficulties. ${ }^{22}$ In the present study, we investigated 127 cases of VATS sleeve lobectomy by a single surgeon at Shanghai Pulmonary Hospital to evaluate our learning curve using CUSUM analysis. Efficacy and proficiency were achieved after 30 cases and 90 cases, respectively. The learning curve effects were obvious with significantly improved perioperative outcomes (Figure 4).

Since the first thoracoscopic sleeve lobectomy was reported in $2002,{ }^{23}$ several studies reported the successful conduction of this surgical approach in hand of experienced surgeons. ${ }^{20,21,24-27}$ Although previous studies had demonstrated the safety and feasibility of VATS sleeve lobectomy despite its technical difficulties, none of them explored the learning phase of this complex procedure. The analysis in our current study is a valuable supplement for several reasons. On the one hand, we point out the time course and caseload required to achieve proficiency by rendering the learning curve, which is profitable for future mentorship. On the other hand, we investigate several measures that could improve perioperative outcomes during the learning process.
On visual inspection of the CUSUM analysis displayed in Figure 1, the curve is ascending overall initially. After 30 cases, the curve keeps relatively stable in an interval. Finally, there is a clear dip at the 90th case (Figure 1). Hence, we identified 3 phases based on these 2 inflection points. In Phase I, the operative time 194 (173-233) minutes was longer than the mean, showing that the surgeon is still in the learning phase. In Phase II, the operative time 172 (142-215) minutes was close to the average, which meant that the physician was able to perform the operation independently with efficacy. While in Phase III, the operative time 138 (117-164) minutes was significantly shorter than the average, indicating that proficiency had been achieved.

Operative time and blood loss are considered major indexes of surgical proficiency. A significant decrease concerning operative time and estimated blood loss was observed in all 3 phases (Figure 2, A). The operative time and blood loss in Phase III, 138 (117-164) minutes and $50(50-100) \mathrm{mL}$, was shorter than the shortest reported operative time and blood loss in the series of $\mathrm{Li}$ and Wang, ${ }^{26} 165$ (120-280) minutes and $150(50-265 \mathrm{~mL})$, respectively. Several reasons may explain the improvement. First, bronchial anastomosis, as the most important part of sleeve lobectomy, is the main step to prolong the operative time in the initial experience. ${ }^{22}$ During the operation, we adopted continuous suture for the both cartilage and membranous portion, which could smooth the operation by reducing the winding of stitches. Besides, bleeding control was more challenging and time-consuming in the initial cases. However, with the improvements of hand skills and familiarity with the instruments, we have been 
able to achieve proficient anastomosis and bleeding control.

In addition, the duration of chest drainage and the length of hospital stays should also be considered. Patients in Phase III had significantly faster removal of chest drainage tubes, $4.08 \pm 1.25$ days, and shorter postoperative stays, $5.39 \pm 1.55$ days (Figure 3). These results were much shorter than those published by Zhou and colleagues, ${ }^{21}$ $7.5 \pm 1.7$ days and $11.6 \pm 2.8$ days, respectively. This may not only benefit from the improvement of surgical skills but also the progress on perioperative management. We optimized perioperative management by introducing the concept of enhanced recovery after surgery. Early withdrawal of electrocardiogram monitoring and activity such as deep breathing and chest expansion were recommended to improve postoperative recovery. In addition, the increasing use of unipotal thoracoscopic surgery may lead to better short-term surgical outcomes and faster recovery. However, these values are longer than those reported by Mahtabifard and colleagues, ${ }^{25} 3$ (2-6) days and 3 (2-8) days, respectively. The potential reason might be that the lesion size in our cohort was larger.

The rate of severe postoperative complications ( $\geq$ III) was significantly reduced as more cases were performed $(P=.025$, Phase I vs II, see Table 2$)$. The most common complication in our study was pneumonia, which occurred in 16 patients (12.6\%). Bronchopleural fistula and prolonged air leak were 2 important factors to reflect the surgical skills of the surgeon. In the present study, there were 4 patients $(3.1 \%)$ who developed bronchopleural fistula and 9 patients $(7.1 \%)$ who developed prolonged air leaks. Our overall results were greater than those in the series of Gao and colleagues, ${ }^{20} 2$ patients (5.1\%) with pneumonia, 1 patient $(2.6 \%)$ with bronchopleural fistula, and 1 patient $(2.6 \%)$ with prolonged air leak. The potential reason might be that we included older patients with a worse percentage of forced expiratory volume in 1 second, which may result in a poor recovery after operation. During the operation, we introduced 2 methods to reduce anastomotic complications. We adjusted the interval of the suture to compensate for the size differences between the 2 bronchi $^{28}$ and prepared an intercostal pedicle flap to encircle bronchial anastomosis, which would preserve the continuity of the airway. ${ }^{29,30}$

Arguments against broadening the adoption of VATS sleeve lobectomy include the high rate of recurrence. ${ }^{31}$ In our study, the rate of both local and distal recurrence was decreased as more cases were performed, but the difference was not significant. However, the rate of recurrence in patients with malignant tumors, $28.6 \%$, was much lower than reported by Gao and colleagues ${ }^{20} 43.6 \%$, in which the median follow-up time, 44.0 months, was much longer than ours, 32.4 months. And the rate of recurrence in Phase III, of which with more patients of advanced stage should have been greater than Phase I and Phase II, was inversely much lower, $17.1 \%$. The potential reason was that we included patients with benign lesions and the follow-up time in Phase III is relatively shorter.

Based on our experience, we found several tips that may help lessen the learning curve of VATS sleeve lobectomy. Compared with the reconstruction of the second carina on the left side, right bronchial sleeve resection is usually easier because the left main bronchus is often hidden in the rear of the left pulmonary artery. Thus, conducting the right upper lobe sleeve resection first might be suitable, as it is the most common sleeve lobectomy. As for the number of incisions with which to start, there were no fixed standards. It might be best to determine the operation methods based on the surgeons' preference and specialization. During the operation, we improved our suturing technique by using continuous and interrupted suturing for the membranous and cartilaginous portions of the bronchus, respectively, which resulted in less suture tangling and quick anastomosis. In addition, we recommend using monofilament absorbable sutures for smooth placement and sliding of knots rather than nonabsorbable sutures, which would irritate the airway and cause significant postoperative cough. $^{32}$

Although current and previous studies have yielded promising results, VATS sleeve lobectomy should be implemented with caution. Before conducting the surgery efficaciously, surgeons should be experienced and trained in both open and thoracoscopic surgery techniques. Bronchial anastomosis, parenchymal resections, and hemorrhage control are all skills requiring much experience. Simulations may be able to substitute some of the case numbers required to achieve proficiency in a complex operation. Nakada and colleagues ${ }^{33}$ invented a 3-dimensional printed thoracic model with high fidelity to improve new surgeons' cognitive and technical skills.

The introduction of the technique to additional surgeons within a high-volume center is safe and can be done without compromising the outcomes. In initial experience, operation should be under sophisticated supervision to smooth the process and prevent unnecessary emergency, while gradually working toward decreasing supervision.

\section{Limitations}

There still exist some limitations in our study. First, this study is a retrospective study, in which the selection bias is inevitable. Second, the use of data from only one single surgeon limits the introduction of our results to a general population of learners. Third, there is no definite evidence to demonstrate whether different nursing teams, residents, and fellows for each procedure would impact the learning curve. In addition, patients who underwent sleeve lobectomy combined with vascular sleeve resection or other pulmonary resections would impact the learning curve of this procedure. Finally, the follow-up time for each patient 
was uneven, some of which were not long enough to provide accurate data on survival outcomes. For this study, we focused on the evaluation of perioperative outcomes; study end points such as cost containment and quality of life after operation might be included.

\section{CONCLUSIONS}

The study demonstrated the feasibility and safety of VATS sleeve lobectomy for centrally located lesions. Efficacy is reached after 30 cases, and proficiency is achieved after 90 cases. The perioperative outcomes can be improved as the learning curve develops. Our evaluation of time courses and caseload required to achieve proficiency may provide insight into reasonably allocating the resources during the mentorship and suggesting methods that could help shorten the learning curve.

\section{Conflict of Interest Statement}

The authors reported no conflicts of interest.

The Journal policy requires editors and reviewers to disclose conflicts of interest and to decline handling or reviewing manuscripts for which they may have a conflict of interest. The editors and reviewers of this article have no conflicts of interest.

We thank the biostatistician, Prof Zhang Aihong (Department of Medical Statistics, Tongji University School of Medicine, Shanghai, P. R. China), for the design and guidance of statistical analysis in this research.

\section{References}

1. Rami-Porta R, Call S. Sleeve lobectomy and pneumonectomy: can they really be properly compared? Transl Lung Cancer Res. 2020;9:434-7.

2. Pages PB, Mordant P, Renaud S, Brouchet L, Thomas PA, Dahan M, et al. Sleeve lobectomy may provide better outcomes than pneumonectomy for non-small cell lung cancer. A decade in a nationwide study. J Thorac Cardiovasc Surg. 2017; 153:184-95.e3.

3. Deslauriers J, Gregoire J, Jacques LF, Piraux M, Guojin L, Lacasse Y. Sleeve lobectomy versus pneumonectomy for lung cancer: a comparative analysis of survival and sites or recurrences. Ann Thorac Surg. 2004;77:1152-6; discussion 1156.

4. Berry MF, Worni M, Wang X, Harpole DH, D'Amico TA, Onaitis MW. Sleeve lobectomy for non-small cell lung cancer with N1 nodal disease does not compromise survival. Ann Thorac Surg. 2014;97:230-5.

5. Kim YT, Kang CH, Sung SW, Kim JH. Local control of disease related to lymph node involvement in non-small cell lung cancer after sleeve lobectomy compared with pneumonectomy. Ann Thorac Surg. 2005;79:1153-61; discussion 1153-1161.

6. Tedder M, Anstadt MP, Tedder SD, Lowe JE. Current morbidity, mortality, and survival after bronchoplastic procedures for malignancy. Ann Thorac Surg. 1992;54:387-91.

7. Xie D, Deng J, Gonzalez-Rivas D, Zhu Y, Jiang L, Jiang G, et al. Comparison of video-assisted thoracoscopic surgery with thoracotomy in bronchial sleeve lobectomy for centrally located non-small cell lung cancer. J Thorac Cardiovasc Surg. 2021;161:403-13.e2.

8. Boffa DJ, Dhamija A, Kosinski AS, Kim AW, Detterbeck FC, Mitchell JD, et al Fewer complications result from a video-assisted approach to anatomic resection of clinical stage I lung cancer. J Thorac Cardiovasc Surg. 2014;148:637-43.

9. Liu L, Mei J, Pu Q, Ma L. Thoracoscopic bronchovascular double sleeve lobectomy for non-small-cell lung cancer. Eur J Cardiothorac Surg. 2014;46:493-5.
10. Gonzalez-Rivas D, Fernandez R, Fieira E, Rellan L. Uniportal video-assisted thoracoscopic bronchial sleeve lobectomy: first report. J Thorac Cardiovasc Surg. 2013;145:1676-7.

11. Yu JA, Weyant MJ. Techniques of bronchial sleeve resection. Semin Cardiothorac Vasc Anesth. 2012;16:196-202.

12. Merritt RE, Hoang CD, Shrager JB. Lymph node evaluation achieved by open lobectomy compared with thoracoscopic lobectomy for N0 lung cancer. Ann Thorac Surg. 2013;96:1171-7.

13. Denlinger CE, Fernandez F, Meyers BF, Pratt W, Zoole JB, Patterson GA, et al. Lymph node evaluation in video-assisted thoracoscopic lobectomy versus lobectomy by thoracotomy. Ann Thorac Surg. 2010;89:1730-5; discussion 1736.

14. Medbery RL, Gillespie TW, Liu Y, Nickleach DC, Lipscomb J, Sancheti MS, et al. Nodal upstaging is more common with thoracotomy than with VATS during lobectomy for early-stage lung cancer: an analysis from the National Cancer Data Base. J Thorac Oncol. 2016;11:222-33.

15. Detterbeck FC, Boffa DJ, Kim AW, Tanoue LT. The eighth edition lung cancer stage classification. Chest. 2017;151:193-203.

16. Charlson ME, Pompei P, Ales KL, MacKenzie CR. A new method of classifying prognostic comorbidity in longitudinal studies: development and validation. $J$ Chronic Dis. 1987;40:373-83.

17. Dindo D, Demartines N, Clavien PA. Classification of surgical complications: a new proposal with evaluation in a cohort of 6336 patients and results of a survey. Ann Surg. 2004;240:205-13.

18. Grunkemeier GL, Wu YX, Furnary AP. Cumulative sum techniques for assessing surgical results. Ann Thorac Surg. 2003;76:663-7.

19. Noyez L. Control charts, Cusum techniques and funnel plots. A review of methods for monitoring performance in healthcare. Interact Cardiovasc Thorac Surg. 2009;9:494-9.

20. Gao HJ, Jiang ZH, Gong L, Ma K, Ren P, Yu ZT, et al. Video-assisted vs thoracotomy sleeve lobectomy for lung cancer: a propensity matched analysis. Ann Thorac Surg. 2019;108:1072-9.

21. Zhou S, Pei G, Han Y, Yu D, Song X, Li Y, et al. Sleeve lobectomy by videoassisted thoracic surgery versus thoracotomy for non-small cell lung cancer. $J$ Cardiothorac Surg. 2015;10:116.

22. Rendina EA, Venuta F, Ciriaco P, Ricci C. Bronchovascular sleeve resection. Technique, perioperative management, prevention, and treatment of complications. J Thorac Cardiovasc Surg. 1993;106:73-9.

23. Santambrogio L, Cioffi U, De Simone M, Rosso L, Ferrero S, Giunta A. Videoassisted sleeve lobectomy for mucoepidermoid carcinoma of the left lower lobar bronchus: a case report. Chest. 2002;121:635-6.

24. Nakanishi K. Video-assisted thoracic surgery lobectomy with bronchoplasty for lung cancer: initial experience and techniques. Ann Thorac Surg. 2007;84:191-5.

25. Mahtabifard A, Fuller CB, McKenna RJ Jr. Video-assisted thoracic surgery sleeve lobectomy: a case series. Ann Thorac Surg. 2008;85:S729-32.

26. Li Y, Wang J. Video-assisted thoracoscopic surgery sleeve lobectomy with bronchoplasty: an improved operative technique. Eur J Cardiothorac Surg. 2013;44:1108-12.

27. Agasthian T. Initial experience with video-assisted thoracoscopic bronchoplasty. Eur J Cardiothorac Surg. 2013;44:616-23.

28. Kutlu CA, Goldstraw P. Tracheobronchial sleeve resection with the use of a continuous anastomosis: results of one hundred consecutive cases. J Thorac Cardiovasc Surg. 1999;117:1112-7.

29. Rendina EA, Venuta F, Ricci P, Fadda GF, Bognolo DA, Ricci C, et al. Protection and revascularization of bronchial anastomoses by the intercostal pedicle flap. $J$ Thorac Cardiovasc Surg. 1994;107:1251-4.

30. Storelli E, Tutic M, Kestenholz P, Schneiter D, Opitz I, Hillinger S, et al. Sleeve resections with unprotected bronchial anastomoses are safe even after neoadjuvant therapy. Eur J Cardiothorac Surg. 2012;42:77-81.

31. Hong TH, Kim J, Shin S, Kim HK, Choi YS, Zo JI, et al. Clinical outcomes of microscopic residual disease after bronchial sleeve resection for non-small cell lung cancer. J Thorac Cardiovasc Surg. February 29, 2020 [Epub ahead of print].

32. Gonzalez-Rivas D, Yang Y, Sekhniaidze D, Stupnik T, Fernandez R, Lei J, et al. Uniportal video-assisted thoracoscopic bronchoplastic and carinal sleeve procedures. J Thorac Dis. 2016;8:S210-22.

33. Nakada T, Noda Y, Kato D, Mori S, Asano H, Matsudaira H, et al. Simultaneous two-dimensional and three-dimensional simulation of thoracoscopic sleeve lobectomy: a quick understanding of pitfalls. Ann Thorac Surg. 2020;109:e383-5.

Key Words: video-assisted thoracoscopic surgery, sleeve lobectomy, learning curve, perioperative outcomes 


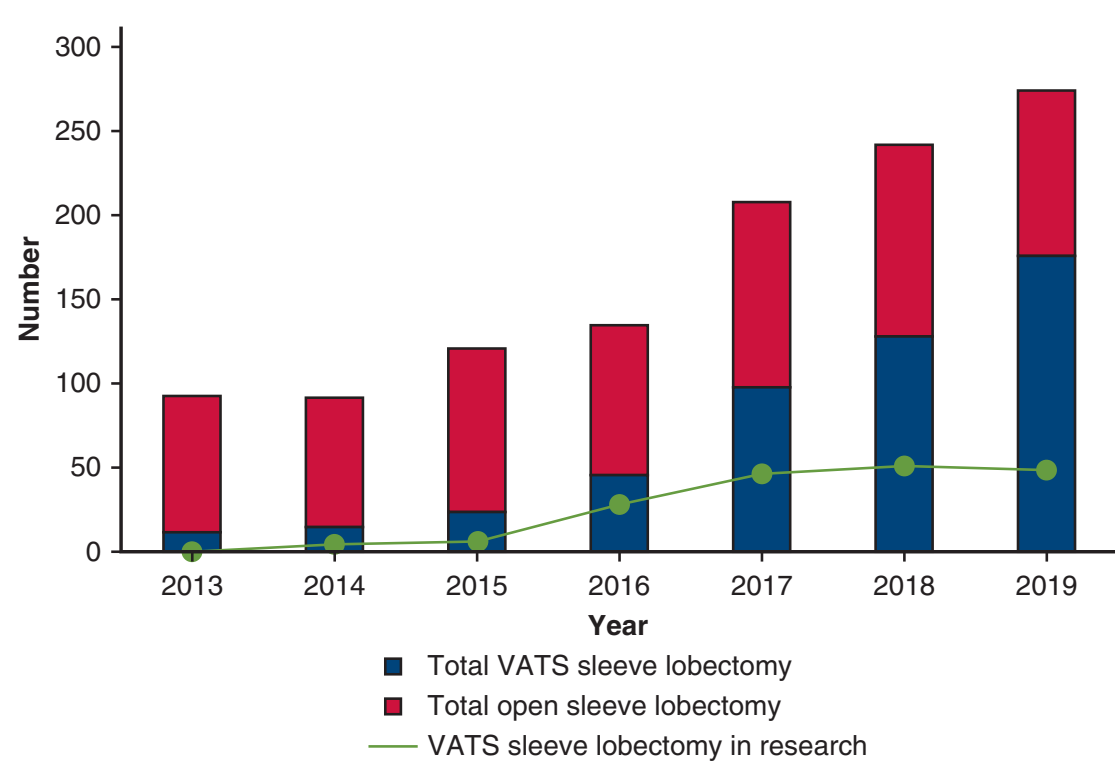

FIGURE E1. The total number of sleeve lobectomy performed in our institution. The blue box reflects the number of VATS sleeve lobectomy in our institution. The red box reflects the number of open sleeve lobectomy in our institution. The green line reflects the number of VATS sleeve lobectomies performed by the surgeon in our study. VATS, Video-assisted thoracic surgery.

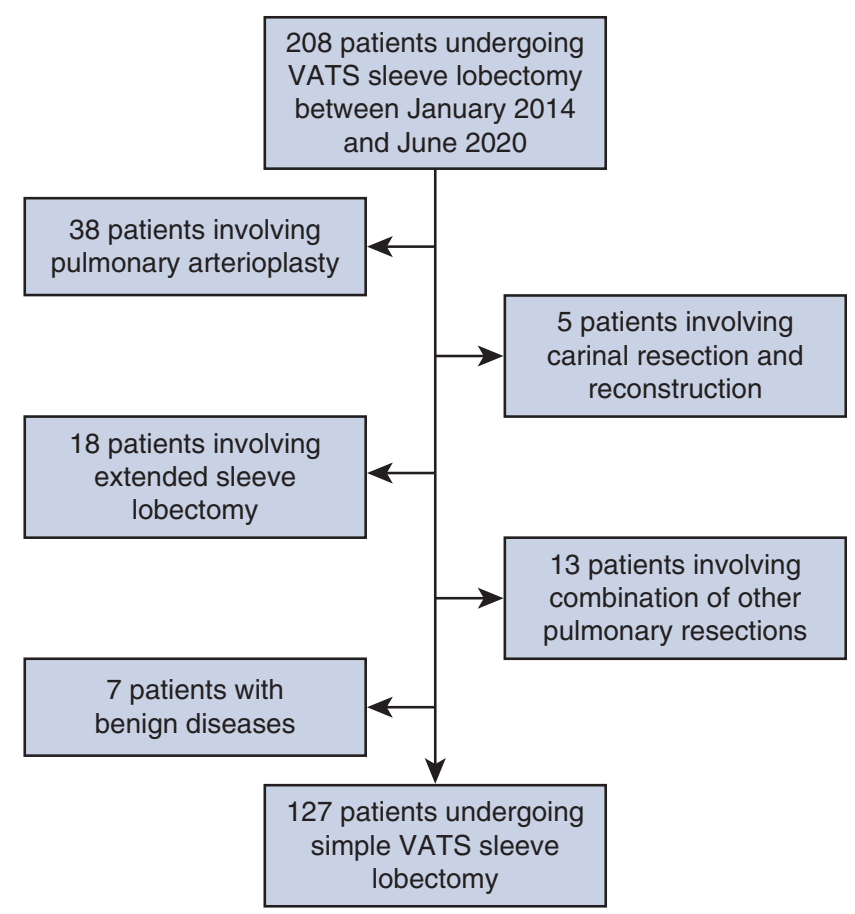

FIGURE E2. The flowchart of patient inclusion. VATS, Video-assisted thoracic surgery. 


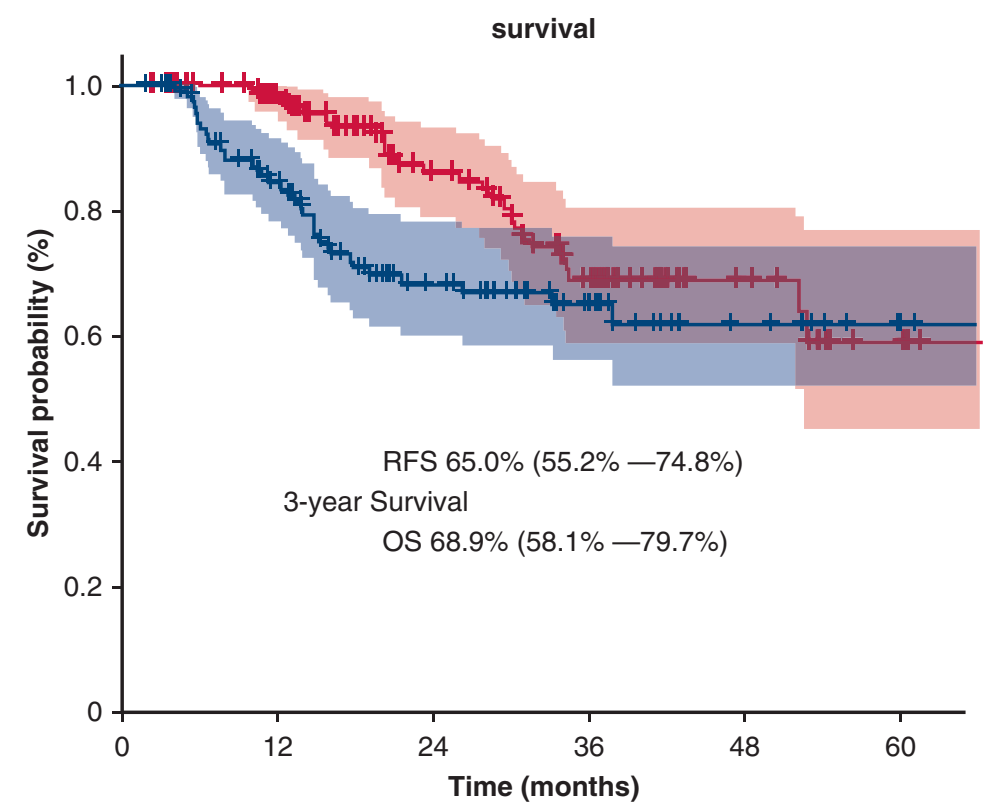

\begin{tabular}{|c|c|}
\hline \multicolumn{2}{|c|}{ Number at risk } \\
\hline+ os & \\
\hline$+\mathrm{RFS}$ & \\
\hline
\end{tabular}

105

90

65
50

36
29

16

5

5

FIGURE E3. Five-year overall survival and recurrence-free survival curves of all series. The red line reflects the overall survival of all series. The blue line reflects the recurrence-free survival of all series. $O S$, Overall survival; RFS, recurrence-free survival. 